mortality would be eliminated from major surgery. Our multiunit study of patients with a high risk of fatal PE undergoing various major surgical procedures showed that heparin significantly reduced the incidence of fatal postoperative PE.

We thank Mr J M Buchanan, Mr V V Kakkar, and Mr A F Higgins for their help in the preparation of this article; Dr M M Koshi for his help in the project; Messrs P M Higgins, W Sewell, L J Lawson, J G Gray, and E G Brewin, who allowed patients under their care to be included in this trial; the consultant pathologists for their necropsy reports; Dr F Hails, coroner, Stoke-on-Trent, for his co-operation; Mrs S Docksey for her painstaking secretarial work; and, finally, but not least, the nursing staff and junior colleagues for their help.
Requests for reprints should be addressed to Mr S Sagar, Department of Surgery, King's College Hospital Medical School, London SE5 8RX.

\section{References}

1 Kakkar, V V, et al, Lancet, 1972, 2, 101

2 Sagar, S, British Medical fournal, 1974, 1, 153.

3 Sagar, S, fournal of the Royal College of Surgeons of Edinburgh, in press.

${ }^{4}$ Kakkar, V V, et al, Lancet, 1971, 2, 669.

5 Bonnar, J, and Walsh, J, Lancet, 1972, 1, 614.

6 Sabri, S, Roberts, V C, and Cotton, L T, British Medical fournal, 1971, $3,82$.

${ }^{7}$ Browse, N L, and Negus, D, British Medical fournal, 1970, 3, 615.

\title{
Comparison of fibreoptic endoscopy in acute upper gastrointestinal haemorrhage in Africans and Europeans
}

\author{
A C B WICKS, G E THOMAS, D J CLAIN
}

British Medical fournal, 1975, 4, 259-260

rhage. One African and nine Europeans had previously been operated on for peptic ulceration. The African patients were seen at Harari Hospital, which is the major referral centre for a population of 2000000 and the general hospital for the Greater Salisbury area. The European patients were referred to one of us (DJC) in a private consulting practice. Classified according to six social grades, ${ }^{2} 4 \%$ of Africans and $32 \%$ of Europeans were in classes 1 and 2 (professional and skilled), and $36 \%$ of Africans and $1.5 \%$ of Europeans were in classes 5 and 6 (unskilled and labourers). Within the gradings there was a large pay differential between the races. The lower social grades of Africans consumed significantly more maize meal and less spirits, meat, eggs, potatoes, fish, and jam than the Europeans.

Patients received diazepam $(5-20 \mathrm{mg})$ by intravenous injection after a detailed explanation of the nature of the procedure. Hyoscine butylbromide (20-40 mg) was often used to reduce peristalsis. An Olympus GIF-D end-viewing panendoscope or an Olympus JFB2 side-viewing duodenoscope, or both, were used. The endoscope was passed with the patient in the left lateral position. to herbal medicines, were more common in the Africans
but the difference was not significant. The study was not designed to determine reduced mortality since the introduction of endoscopy, but management, especially in the Africans, was aided by early recognition of haemorrhage from oesophageal varices and acute gastric erosions.

\section{Introduction}

Flexible fibreoptic instruments have revolutionised the early diagnosis of gastrointestinal haemorrhage and have led to a reassessment of the incidence of underlying lesions. ${ }^{1}$ We used panendoscopy to compare the causes of gastrointestinal bleeding in two racial groups of widely different socioeconomic status and dietary habit. We describe below our experience in African and European patients.

\section{Patients and methods}

From June 1972 to July 1974222 patients (138 Africans and 84 Europeans) underwent endoscopy for upper gastrointestinal haemor-

\footnotetext{
Department of Medicine, University of Rhodesia, Salisbury, Rhodesia

A C B WICKS, MD, MRCP, senior lecturer

G E THOMAS, MRCP, lecturer

D J CLAIN, MD, MRCP, consultant physician
}

\section{Results}

The mean age of the Africans was lower (38 years, range 12-76 years) than that of the Europeans (51 years, range 19-82 years), and the male: female ratio was about $3: 1$ in both races. These patients constituted $37 \%$ of the Africans and $26 \%$ of the Europeans referred for upper gastrointestinal endoscopy during the two-year period. Altogether $110(80 \%)$ of the Africans and $(79 \%) 66$ of the Europeans presented with both haematemesis and melaena; the remainder had melaena alone. Forty-one $(30 \%)$ of the Africans and $26(31 \%)$ of the Europeans underwent endoscopy within two days of bleeding, $112(81 \%)$ and $64(76 \%)$ within seven days, and $26(19 \%)$ and $20(24 \%)$ after seven days.

Table I shows the results in both groups. There were no complications. A bleeding source was not found in 18 Africans and 12 Europeans. One African was found to have colonic bleeding at surgery, and in a second necropsy showed no cause of bleeding. The endoscope failed to enter the duodenum in three Africans, who were subsequently operated on for duodenal ulcer. Nearly half the examinations with negative findings in the Africans occurred seven to 14 days after haemorrhage. Seven of the 12 Europeans with negative findings underwent endoscopy more than a week after bleeding, and eight had presented with melaena alone. One had a gastric and another a duodenal ulcer at operation.

The percentage of positive diagnoses was similar for the Africans and Europeans. Duodenal ulcers were the commonest cause of bleeding in both groups, followed by gastric ulcers, which were present in $17.3 \%$ of the Africans and $20.2 \%$ of the Europeans. Of the 36 African and 22 European patients with duodenal ulcers only four and 
TABLE I-Comparison of endoscopic findings in Africans and Europeans

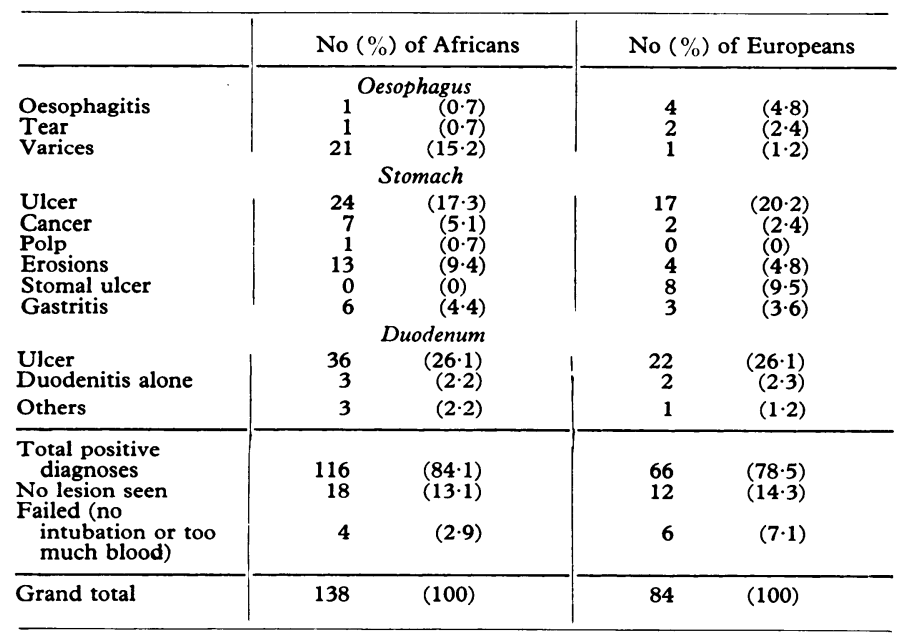

one respectively were women, while of the 24 Africans and 17 Europeans with a gastric ulcer six and eight were women.

There were two major differences between the African and European patients. Anastomotic ulcers were not seen in the Africans, but were present in $9.5 \%$ of the Europeans $(0.05>P>0.001)$, while oesophageal varices were seen in 21 Africans but only one European $(0.01>P>0.001)$. Most of the Africans with varices were heavy beer drinkers and had cirrhosis; only five were women. Two patients were under the age of 20 and had bilharzial fibrosis of the liver with portal hypertension.

Gastric erosions accounted for $9.4 \%$ of the bleeding in the Africans, which was not significantly higher than the European incidence. Among the 13 Africans with gastric erosions five had taken traditional medicine of unknown content from a herbalist. The lesions were in the fundus or high on the lesser curve of the stomach and had a characteristic, well-defined, fleshy, and haemorrhagic appearance. There was a history of recent aspirin ingestion in about a third of the patients in both groups with gastric erosions.

Multiple Lesions - Table II shows that multiple lesions were more common in the Africans $(10.1 \%)$ than in the Europeans $(4.8 \%)$, but the difference was not statistically significant. Though oesophagitis as a primary site of bleeding was seen only once in an African it was an associated finding in three others.

Emergency Surgery-Emergency surgery was performed on four Africans with bleeding duodenal ulcers and six with gastric ulcers. Seven Europeans proceeded to operation, four with a duodenal and three with a gastric ulcer.

TABLE II-Multiple lesions present on endoscopy in 14 Africans and four Europeans

\begin{tabular}{|c|c|c|c|c|}
\hline & \multicolumn{2}{|l|}{ Africans } & \multicolumn{2}{|l|}{ Europeans } \\
\hline & Associated finding & No & Associated finding & No \\
\hline Oesophageal varices & $\begin{array}{l}\text { Gastric ulcer } \\
\text { Oesophagitis } \\
\text { Gastric erosion } \\
\text { Gastric varices }\end{array}$ & $\begin{array}{l}1 \\
1 \\
1 \\
1\end{array}$ & & \\
\hline Gastric ulcer & $\begin{array}{l}\text { Gastric phytobezoar } \\
\text { Oesophagitis }\end{array}$ & $\begin{array}{l}1 \\
1\end{array}$ & Oesophagitis & 1 \\
\hline Duodenal ulcer & $\begin{array}{l}\text { Gastric ulcer } \\
\text { Gastric erosions } \\
\text { Oesophagitis }\end{array}$ & $\begin{array}{l}3 \\
3 \\
2\end{array}$ & Gastric ulcer & 1 \\
\hline Stomal ulcer & & & $\begin{array}{l}\text { Jejunitis } \\
\text { Oesophagitis }\end{array}$ & $\begin{array}{l}1 \\
1\end{array}$ \\
\hline
\end{tabular}

\section{Discussion}

European and African Rhodesians live under contrasting socioeconomic and dietary circumstances, which prompted us to compare the pattern of upper gastrointestinal bleeding in the two groups. We have found no comparable figures on African patients, but in three series of panendoscopy in upper gastrointestinal bleeding from the USA ${ }^{3-5}$ and two from the $\mathrm{UK}^{16}$ the findings were essentially similar to those in our European patients. Notable differences included varices in $16 \%$ of patients in the study by Katon and Smith ${ }^{4}$ and a higher incidence of erosions and gastritis reported by Sugawa et $a l,{ }^{5}$ and Forrest et al. ${ }^{6}$ The prevalence of gastric and duodenal ulceration was the same in both Rhodesian racial groups, which was surprising as peptic ulceration is supposed to be uncommon in Africans. ${ }^{7}$ The complete absence of stomal ulcers in African patients may be due to the rarity of major gastric surgery for peptic ulceration. We confirmed the value of endoscopy in the Europeans with stomal ulcers, as five had had negative barium meal results.

Before performing endoscopy we though that oesophageal varices were the commonest source of bleeding in Africans, but peptic ulceration proved to be the prime cause. The high incidence of both cirrhosis and hepatoma in Rhodesian Africans explains the high proportion $(15 \%)$ of Africans with varices. This is a much greater proportion than was found in other series, except Katon and Smith's, ${ }^{4}$ or among our European patients. In a recent study $57 \%$ of patients with hepatoma ${ }^{8}$ and $61 \%$ of newly diagnosed cirrhotics ${ }^{9}$ had varices seen endoscopically. In our patients with varices we did not find the common association with bleeding from peptic ulcers or other lesions that has been documented elsewhere. ${ }^{10}$

Gastric erosions were often seen in Africans, and when there was a history of ingestion of herbal medicine the lesions were characteristic and always found in the proximal portion of the stomach. Only a third of gastric erosions, in both racial groups, was associated with aspirin ingestion. Bleeding oesophagitis was nearly seven times more common in Europeans; this difference is in keeping with the rarity of hiatus hernias in Africans, ${ }^{11}$ but it did not reach statistical significance.

Multiple lesions in the Africans (10\%) and Europeans (5\%) were less common than in other series $(15-40 \%) .{ }^{14-6}$ The incidence of positive findings was similar in both our racial groups and agrees with that in other studies. ${ }^{136}$

A third of our patients were examined in the first two days. Most patients in our series in whom nothing abnormal was found had bled at least a week before examination, which further emphasized the importance of early endoscopy in acute gastrointestinal haemorrhage. ${ }^{136} \mathrm{~A}$ similar percentage of patients with ulcers in both races required emergency surgery, despite the younger age group and lack of atherosclerosis in Africans.

Endoscopy has been an invaluable aid in both our communities in the management of gastrointestinal haemorrhage. It has highlighted unexpected similarities and differences between the two racial groups in Rhodesia. We have no proof of reduced mortality since the inception of endoscopy as comparable groups of patients were not previously investigated in our hospitals. Nevertheless, the early recognition, especially in the African, of bleeding from oesophageal varices and gastric erosions has facilitated management.

\section{References}

1 Cotton, P B, et al, British Medical fournal, 1973, 2, 505.

2 Castle, W, Measurement of Socioeconomic Status in an Urban African Community, in preparation.

${ }^{3}$ Allen, H M, Block, M A, and Schuman, B M, Archives of Surgery, $1973,106,450$

4 Katon, R M, and Smith, F W, Gastroenterology, 1973, 65, 728.

5 Sugawa, C, et al, Archives of Surgery, 1973, 107, 133.

6 Forrest, J A H, Finlayson, N D C, and Sherman, D J C, Lancet, 1974, 2, 394.

7 Gelfand, M, Central African fournal of Medicine, 1974, 20, 100.

8 Thomas, GE, et al, in preparation.

Wicks, A C B, et al, in preparation.

10 Waldram, R, et al, British Medical fournal, 1974, 4, 94.

11 Gelfand, M, The Sick African, 3rd edn Cape Town, Juta, 1957. 